\title{
Risk-based Optimization of Sensor Distribution in Roof Constructions - A Conceptual Study
}

\author{
Klodian Gradeci ${ }^{1, *}$, Berit Time ${ }^{1}$, Lars Gullbrekken ${ }^{1}$ \\ ${ }^{1}$ SINTEF, Architecture, Building Materials and Structures, 7034 Trondheim, Norway
}

\begin{abstract}
The objective of placing moisture sensors in roof constructions is to warn about leakage events, and thus avoid undesirable consequences. However, considering that placing an additional sensor is directly related to increasing the total cost of the solution, the distribution and placement of the sensor system should be sought as a risk-based problem seeking for the most optimal solution. This paper conceptualises a riskbased optimization methodology that seeks the optimal solution for the sensor system in roof constructions as the one that maximises the return of investment. The latter is sought as a function of the leakage risk, which is derived as a multiplication of the likelihood that leakage events may occur in a roofing system, and their consequences, defined as the amount of direct (and indirect) costs in case a leakage event occurs. The optimal solution is expressed as the total number of sensors and their geometrical distribution. This conceptual study intends to foster innovative usage of sensor systems within the construction sector to allow owners and contractors to identify and avoid consequences of leakage events in roofing systems.
\end{abstract}

\section{Introduction}

\subsection{Motivation}

In a national $R \& D$ project the authors of this paper aim to develop suitable sensor nodes and system solutions for monitoring and preparedness of roof structure's moisture state in operation. The solution aims to detect leakage events and prevent moisture-induced damages in roofs, and subsequently consecutive consequences to the business and construction such as downtime or damages of goods. The latter can be achieved through early notification of potential leakage incidents. This could result in major societal and private economic savings through longer service life for building and building components, early warning that will limit the impact of moisture-induced damages, improve the risk profile of building owners and prevent downtime for businesses. It will also provide great environmental benefits to society through longer service life and better quality of the building stock and healthy indoor environment.

\subsection{Background: Optimization of sensor placement}

An insight into various sensing and environmental monitoring technologies commonly deployed in buildings by surveying different sensor technologies, wired and wireless communication technologies, and several optimization strategies and mathematical models for sensor placement have been discussed in a recent review (1). The review shows that most of the body of knowledge in this field covers topic discussing sensors and monitoring technologies. While more sensors and monitoring technologies may provide a more accurate representation of the likelihood of leakage events in a roofing system, it will also undoubtedly impact on critical factors such as cost, timelines and complexity (due to additional installations), deployment, commissioning, maintenance and data processing required as part of this process (1). Optimization of sensor placement offers an opportunity to reduce the cost of the system without compromising on the quality of the monitoring approach (2).

During the refurbishment of El Prado Museum in Madrid, there were installed sensors of temperature, relative humidity, measurement of local strain and detection of liquid water (3). No more leaking events were detected since the sensor system was incorporated into the existing roof. Two sensors were placed in the weakest places regarding roof tightness (3). Strategies to optimise the sensor placement have been proposed in other studies including a Maximum-likelihood method, Fisher information matrix, Bayesian loss function and Information Entropy Norm (4-7); however, they were criticized in (8) due to their heuristic nature and therefore, not guaranteeing a practical solution.

A multi-objective optimization problem for minimizing sensor cost, average and worst-case impact damage corresponding to a set of contamination event scenarios was proposed in (9). A set of probabilitydistribution-representative contamination scenarios through grid and random sampling was constructed to compute the overall impact of each scenario. This approach was applied to a five-room and a 14-room building. By comparing the average and worst-case impact, it was showed that by increasing the number of installed sensors, the change in the impact risk objectives is reduced and may not be significant (1). On the other hand, a data-driven approach based on cluster algorithms, data loss approach, and the Pareto principle was applied in an office building to derive the optimal placement of

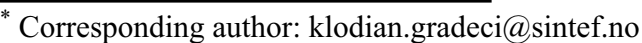


sensors (8). The results revealed that the number of deployed sensors can be reduced to $20 \%$ with minimum loss of information (8).

Previous studies have shown that optimising the sensor placement can be applied as a strategy to reduce the total investment cost while reducing only slightly the level of information. However, an overarching optimization system should additionally and simultaneously account for the following:

- a risk-based optimisation approach considering the return of investment, probability of failure of the sensor system and its consequences;

- a systematic identification of leak-prone spots based on construction and geometry of the roofing system.

\subsection{Aim and Scope}

The aim of this paper is to propose a systematic risk-based optimization methodology that enables informed decision-making about the optimal number and geometric distribution of sensors in roof constructions. This study present the findings from the first stage of this research project, which aim the conceptualization of the risk-based methodology. The latter will be further developed and used as part of a system solution for monitoring and early warning of moisture leakages and it is envisaged to be part of a company's business model.

\section{Proposed risk-based methodology}

\subsection{General principle}

Placing sensors in roof constructions is an investment that aims to warn about leakage events to avoid undesirable consequences. However, considering that placing an additional sensor is directly related to increasing the total cost of the solution, the optimal sensor system should be sought as a risk-based optimization problem. This function seeks for the solution that provides the higher Return of Investment (ROI), and thus, that minimises the total cost of investment while providing the necessary information to detect potential leakage events avoid undesirable and expensive consequences (see Fig. 1). The optimal solution for the sensor system in roof constructions, as a function of ROI, is depending on the following:

- Cost of investment,

- Probability that the system is successful in detection of leakages,

- Expected increase of robustness, depending on:

- Increase of Early Detection of Leakage Events, and

- $\quad$ Leakage Risk.

\footnotetext{
a The model is inspired from 10. Weisbin CR, Rodriguez G, Elfes A, Smith JH. Toward a systematic approach for selection of NASA technology portfolios. Systems engineering. 2004;7(4):285-302.
}

Leakage Risk is dependent on the following:

a) Likelihood of Leakage Events defined as the likelihood that leakages may occur in a roofing system during the anticipated service life of the sensor system. It depends on the following:

- Construction Robustness Index (CRI) defined as an index that measures the susceptibility or robustness of a roof construction to be prone to leakage events. It depends on the construction of the roof and its exposure to weather.

- Leak-prone spots defined as the spots in the roofing system which may be prone to leakage events due to the complexity of the design and geometry characterising the layout of the roofing system. Risk spots are depending only on the overall geometry of the roofing system, and thus independent of the roof construction itself.

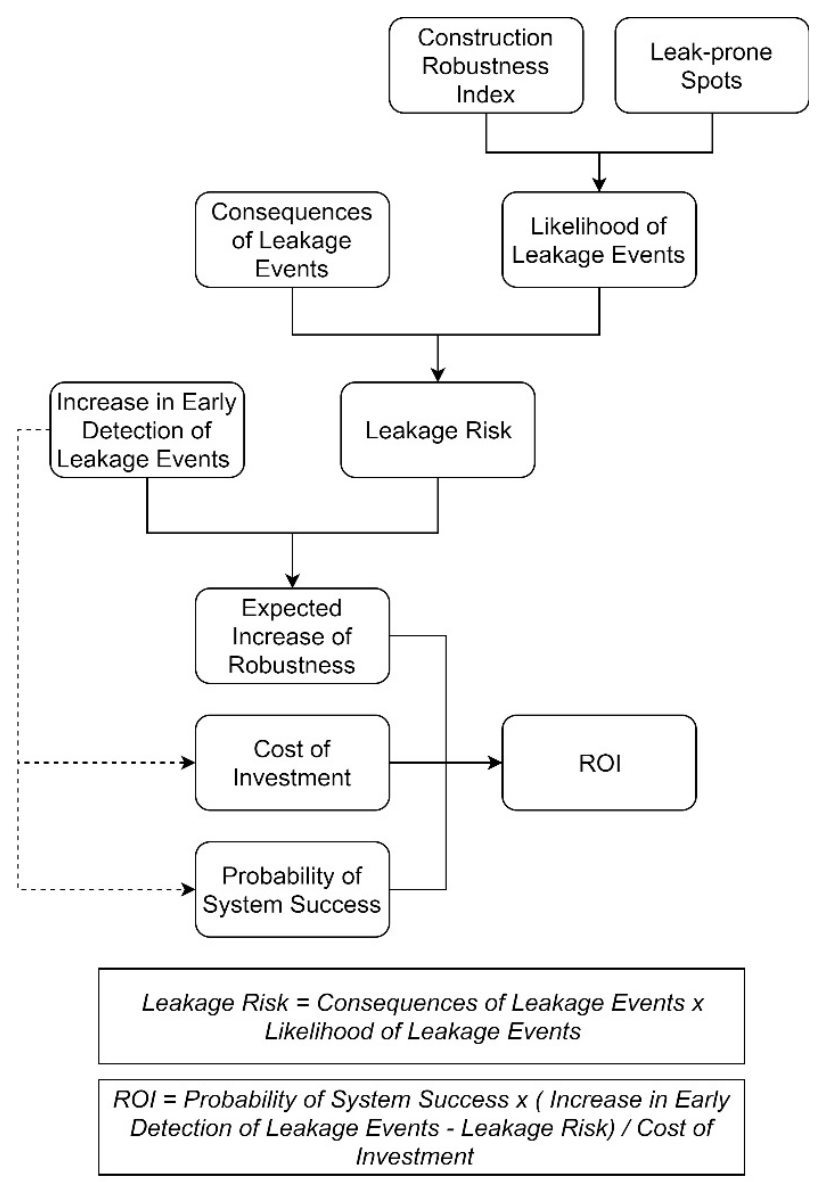

Fig. 1. Return of Investment (ROI) model ${ }^{\mathrm{a}}$

b) Consequences of Leakage Events defined as the direct (and indirect) costs in case a leakage event occurs.

The number of sensors to be distributed should collate to the Leakage Risk. An example of this distribution is provided in Fig. 2. As a hypothetical case where a $N_{\text {Reference, }}$ reference number of sensors per square meter, is provided, the total number of sensors dependent on the associated risk is calculated with the following formula: 


$$
N=N_{\text {reference }} x a_{i}
$$

where:

$N_{\text {Reference }}\left[\right.$ number $\left./ \mathrm{m}^{2}\right]$ - is the reference number of sensors as defined by a preliminary evaluation of the actual market and company's business strategy, and

$a_{i}$ [unitless]- is a coefficient based on the risk of a leakage event and the return of investment as a function of the Leakage Index, consequences and the cost of investment. In Fig. $2, a_{1}<a_{2}<a_{3}<a_{4}<a_{5}$.

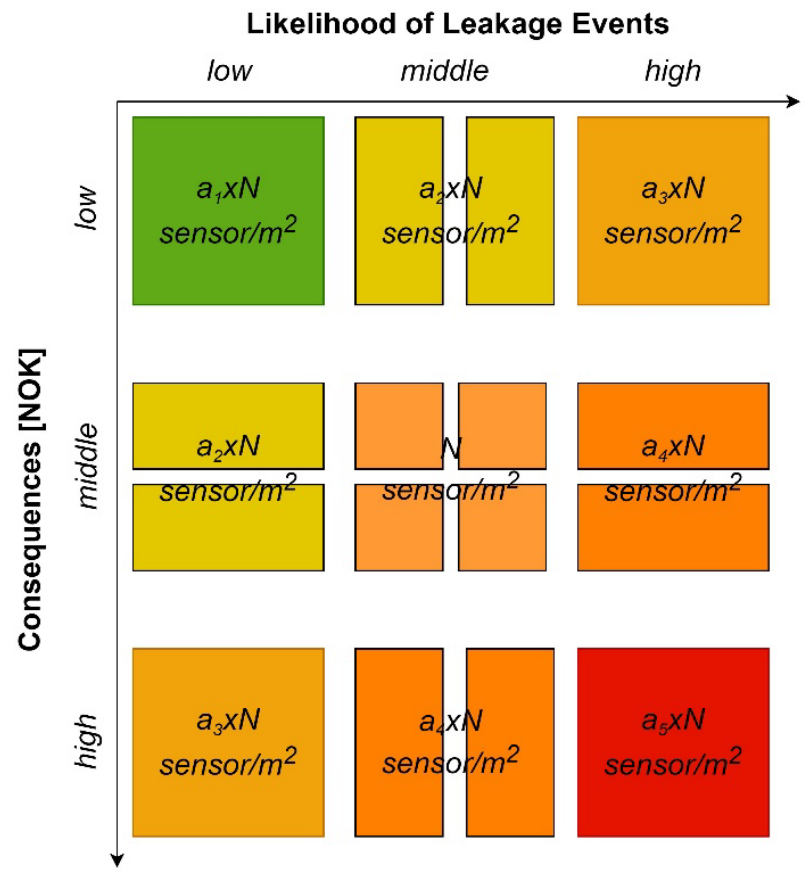

Fig. 2. Leakage Risk matrix. The square in the middle parts of the matrix are separated by a space in the middle to imply potential further categorise (more than 3 ).

\subsection{Workflow}

\subsubsection{General overview}

The workflow for developing optimal geometrical distribution of sensors is presented in Figure 3. The description of each component is provided in the following paragraphs. The optimal sensor distribution in a roofing system is expressed by:

1) $N$, the total number of sensors in the roofing system, and

2) Distribution geometry of the sensors within the roofing system.

The total number of sensors $\mathrm{N}$ is calculated according to the following function:

$$
\boldsymbol{N}=\max \left(N_{1}, N_{2}\right)
$$

$N_{l}$ - is the minimum number of sensors as defined by the risk matrix, and

$N_{2}$ - is the minimum number of sensors as defined by the number of risk spots.

$$
N_{l}=C R I x a_{i} \times N_{\text {Preliminary }}
$$

Where:

$C R I$ - is the Construction Robustness Index,

$a_{i}$ - coefficient based on the consequences, and

$N_{\text {Preliminary }}$ - is the preliminary or reference number of sensors as defined by a preliminary evaluation of market prices of sensors, company's strategy and/or consequences of the specific case study.

\subsubsection{Construction Robustness Index (CRI)}

Construction Robustness Index (CRI) in roof construction is an index that accounts for the ability that a roof construction has to withstand leakage events. It depends on the robustness of the roof construction and how prone to leakage events and moisture failures it may be. This index does not account for the leak-prone spots per se.

Construction Robustness Index is calculated based on different factors describing the roof construction and is expressed as the following:

$$
\begin{aligned}
& \quad C R I=F_{\text {outdoor_climate }} x F_{\text {indoor_climate }} x F_{\text {construction }} x \\
& F_{\text {drainage }} \times F_{\text {workmanship }}
\end{aligned}
$$

The development of CRI coefficients can be sought as the approach to the Factor Method for service life prediction of building materials and components presented in ISO 15686 (11).

Factor $F_{\text {outdoor climate. This factor accounts for the }}$ outdoor climate exposure and it is a product of the macroand micro-climate exposure. The macroclimate part can be based on the Köppen climate classification (12), while the microclimate part can be based on a more local exposure perspective such as the amount of precipitation locally, wind-driven rain, temperature throughout the year, presence of snow, UV radiation.

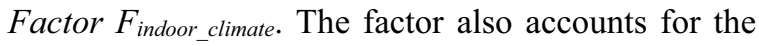
indoor environment where the roofing system is exposed to, e.g moisture production. A classification as provided in different standards, such as (13), may also be employed in this factor.

Factor $F_{\text {construction. This factor accounts for the }}$ construction type of the roofing system. It can be categorised into different load bearing systems, insulation, type and technology of roofing membranes. As an example, in situ cast concrete has a lower susceptibility to leakage events compared to a load bearing construction of steel plates, see Fig. 4. In case free water occurs inside the roof construction, the likelihood of a leakage through the roof construction is larger given load bearing constructions of steel plate, which has a lot of joints,

where: 
compared to a more continuous in situ cast concrete construction.

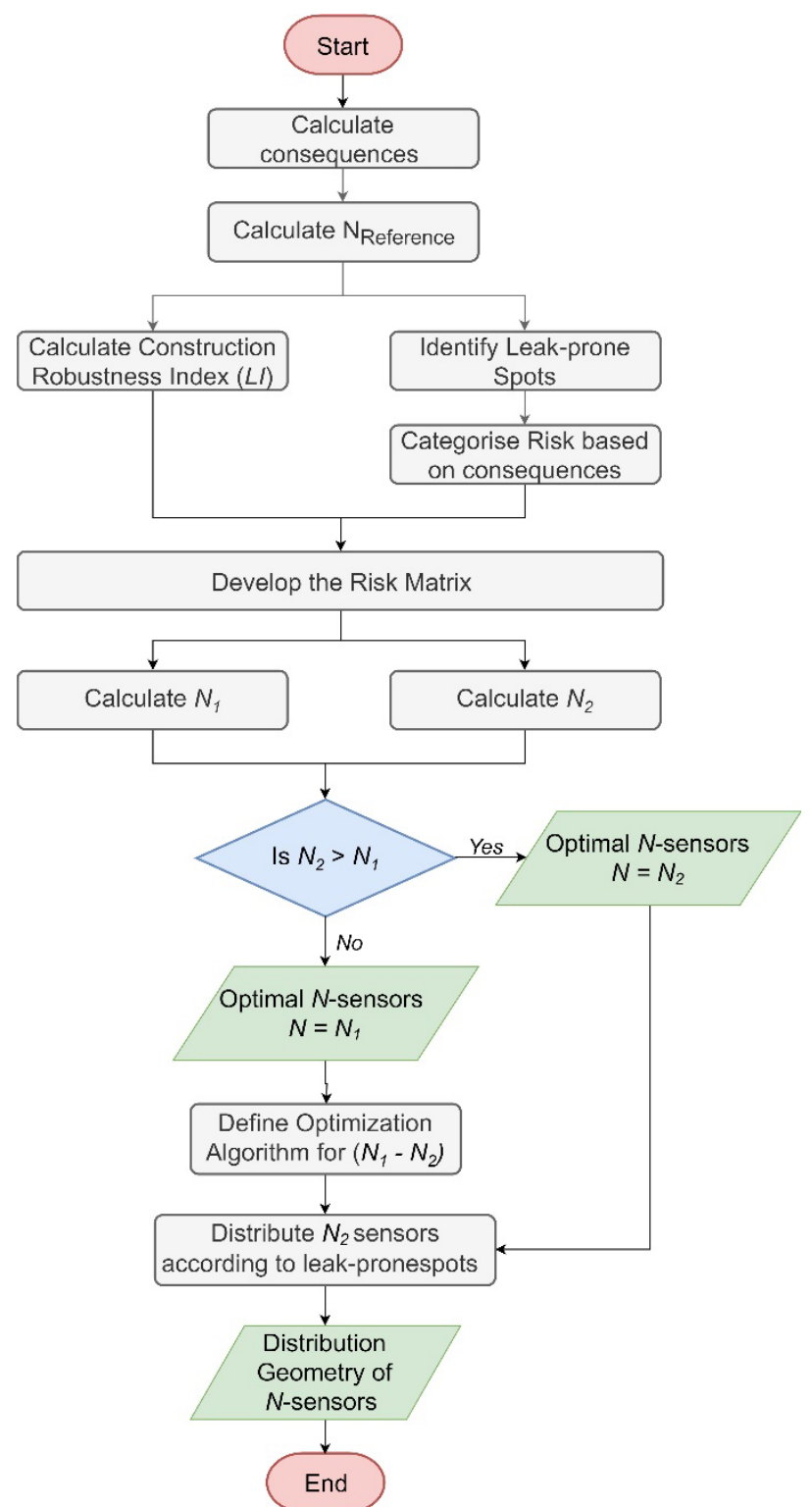

Fig. 3. Workflow for developing the optimal placement of sensors

Factor $F_{\text {drainage. }}$ This factor accounts for the water drainage system of the roof by including the design of the drainage system, the inclination, and availability and distribution of rainwater outlets. The likelihood of water leakage events in the roofing system decreases by increasing the inclination because the latter reduces the likelihood of pools of water/standing water on the roof. The design of the water drainage system, the availability and distribution of rainwater outlets also influence the factor. The likelihood of leakage events is decreased by designing a drainage system which reduces the locations where pools/standing water can occur during and after rain events.

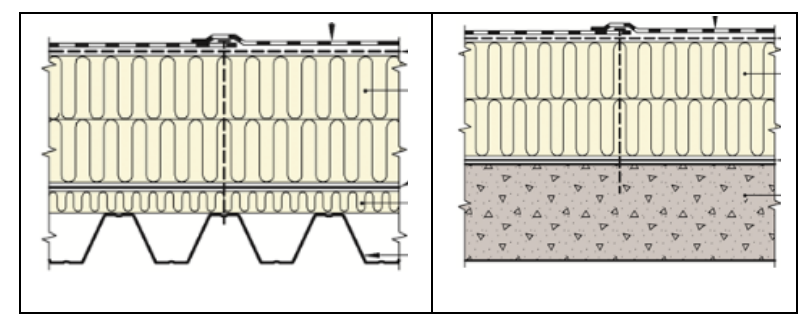

Fig. 4. An example of a roof construction related to a higher susceptibility to leakage events to the left (steel plate) and a construction related to typically lower susceptibility to the right (in situ cast concrete) (14).

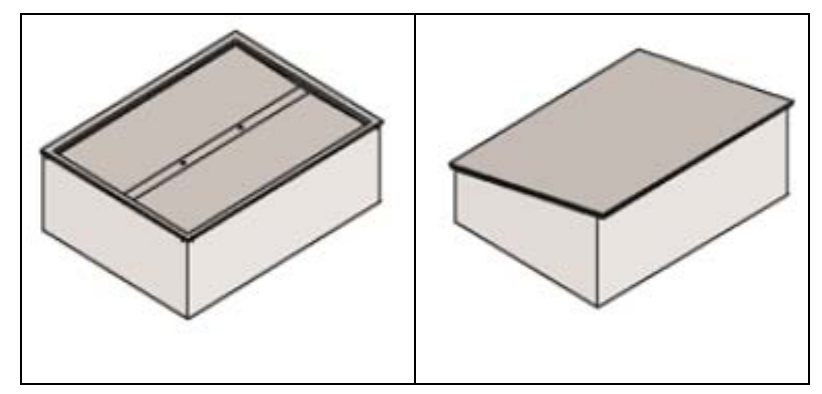

Fig. 5. An example of roofs with different inclinations and drainage systems characterising different robustness to leakage events (15).

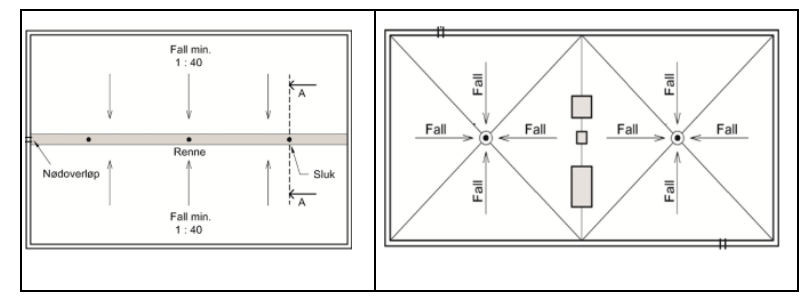

Fig. 6. Examples of roof drainage systems related to different CRI. To the left two-sided fall and to the right fall from several sides (14).

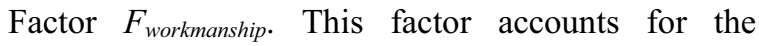
workmanship of the labour and is dependent on the experience of the company, certificates/quality systems, to what extent the work is done according to accepted procedures (including drawings, standards, guidelines, handbooks), and other factors connected to the quality of the labour.

\subsubsection{Leak-prone spots}

Leak-prone spots are defined as the spots of the roofing system which may be prone to leakage events due to the complexities and implications raised by the design of the roof (see figure Fig. 7). This may include parapets, number of corners, connections to other buildings, number of penetrations related to technical systems such as ventilation channels, solar panels etc. These are independent of the roof construction. These spots can be categorised into the following:

- geometrical complexities in the roofing system such as deviations,

- connections between the roof construction and other constructions (parapets, adjacent walls etc.), 
- penetration through the roof and roof membrane such as downpipes,

- ventilation assets or other technical equipment located on the roof.

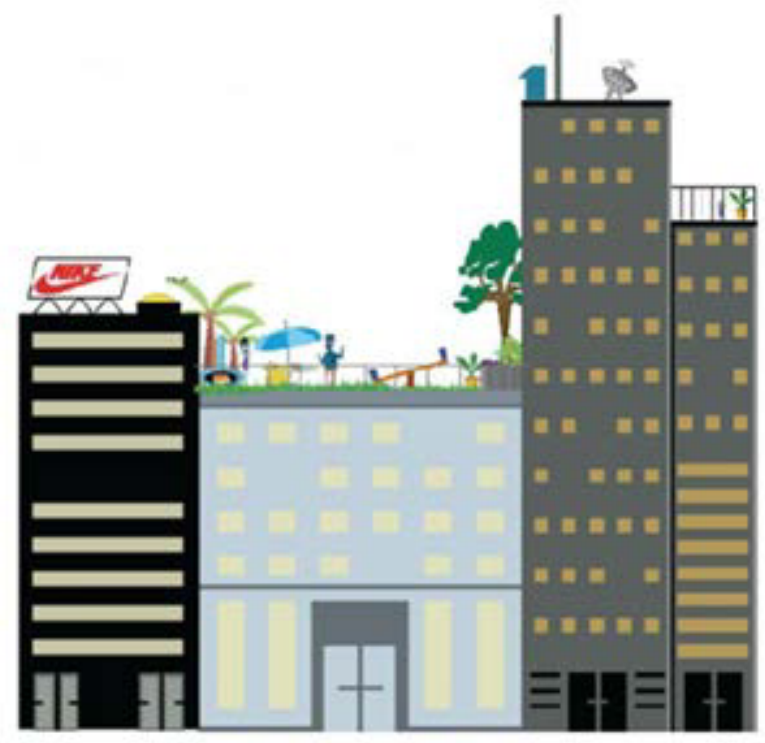

Fig. 7. A general illustration demonstrating a number of potential risk spots (16).

The number of leak-prone spots is directly related to potential number of sensors to be placed in the roofing system, $N_{2}$. Depending on the leak-prone spot, different consequences may be associated to a potential leakage event. These spots can therefore be categorised based on their consequences associated to their placement.

\subsubsection{Deriving consequences of leakage events}

Consequences refer to the cost as consequence of a leakage event, and they are expressed as monetary costs. They depend on the business activity and involved goods under the investigated roofing system. They should also account for the downtime due to maintenance activities and other indirect cost. Low consequence refers to a case where the consequences of a leakage are not associated with high cost, for example a garage/workshop with no moisture sensitive activity or goods. High consequence refers to a case where the consequences of a leakage are associated with high cost, for example a highly moisture sensitive manufacturing or production company.

The consequences are accounted for by coefficients $c_{i}$, which may be categorised based on the total cost in case a leakage occurs (see Table 1). The development of these coefficients may be derived by consulting company-based cost-related reports and analysis regarding refurbishment, downtime and damages as a consequence of leakage events, and also statistics regarding similar claims from insurance data.
Table 1. Relationship between consequences expressed in cost and coefficients $\mathrm{c}_{\mathrm{i}}$.

\begin{tabular}{|c|c|c|}
\hline $\begin{array}{c}\text { Mar } \\
\text { gin } \\
\text { Number }\end{array}$ & Cost Margin & $\begin{array}{c}\text { Coeffici } \\
\text { ent }\end{array}$ \\
\hline 1 currency] & {$[-]$} \\
\hline 1 & $<$ Cost $1 / C_{\text {sensor }}$ & $\mathrm{c}_{1}$ \\
\hline 2 & Cost $1 / \mathrm{C}_{\text {sensor }}<$ Cost $2 / \mathrm{C}_{\text {sensor }}$ & $\mathrm{c}_{2}$ \\
\hline$\ldots$ & $\ldots$ & $\cdots$ \\
\hline $\mathrm{n}-1$ & Cost $\mathrm{n}-2 / \mathrm{C}_{\text {sensor }}<$ Cost $\mathrm{n}-1 /$ & $\mathrm{c}_{\mathrm{n}-1}$ \\
\hline $\mathrm{n}$ & $>\mathrm{C}_{\text {sensor }}$ & $\mathrm{c}_{\mathrm{n}}$ \\
\hline
\end{tabular}

\subsubsection{Optimal distribution of the sensors}

Distribution geometry represents the position and distribution of the selected numbers of sensors. This is dependent on the previous calculated number N1 and N2. The strategy on how to distribute these sensors is provided in the last part of the workflow illustrated in Figure 3. It firstly starts by distributing $\mathrm{N}_{2}$ sensors on the risk spots. Afterwards, if $\mathrm{N} 1$ is larger than N2, then (N1 - N2) is distributed by employing an optimization strategy.

The optimization strategy may be a combination of an algorithmic function and a numerical hygrothermal simulation. A function can be written that generates a list of all possible sensor placement permutations. Specific cases with a fixed number of sensors explore all possible permutation of sensor placement for all typologies in order to gain understanding of an optimal sensor distribution strategy. In addition, spots where the highest concentration of moisture occurs can also be identified by running numerical two- or three-dimensional simulations.

\section{Summary and further research}

This paper conceptualized a risk-based optimization methodology that enables informed decision making about the optimal placement of sensors in roof constructions to avoid undesirable consequences as a result of leakage events. The optimal solution for the sensor system in roof constructions is sought as the one that maximises the return of investment. The outcome is expressed in the total number of sensors and their optimal geometric distribution. The latter are sought as a function of the leakage risk, which is derived as a multiplication of the likelihood that leakage events may occur in a roofing system and their consequences, defined as the amount of direct (and indirect) costs in case a leakage event occurs. The likelihood of leakage events is sought as a function of a) Construction Robustness Index (CRI) defined as an 
index that measures the susceptibility or robustness of a roof construction to be prone to leakage events; and b) Leak-prone spots defined as the spots in the roofing system which may be prone to leakage event due to the complexity of the design and geometry characterising the system.

The proposed methodology is expected to be further developed and tested in real life applications. The methodology is flexible enough to accommodate its further expansion into building envelopes, which may enable a more holistic overview of the total performance of whole buildings.

Continuous measurement data for moisture levels from sensor systems can in the long-term perspective be used to establish better knowledge about vulnerabilities for different types of constructions and frequent building moisture-induced damages. The knowledge today is largely based on the experience of a limited range of buildings and types of buildings, where only qualitative "investigation" of damage is carried out. Continuous data collection for moisture measurements in constructions like roofs are rare. Therefore, good quality data from many buildings will help to gain better and more comprehensive knowledge of risk profiles for different types of buildings and likelihoods of leaks and building damages.

This study presented the findings from the first stage of the project aiming the conceptualisation of the riskbased optimization methodology. The second stage will demonstrate the feasibility of this methodology. The detailed description of the different factors included in the CRI will be developed. Co-creation activities with partners from the building sector will take place to form the methodology and the tool as applicable as possible for practise use. Subsequently, the proof of concept will be upscaled in the last stage of the project. This conceptual study intends to foster innovative usage of sensor system within the construction sector allowing owners and contractors the identification of leakage event in proper time to take proactive measure, and hence, avoid undesirable consequences of leakage events.

\section{References}

1. Hayat H, Griffiths T, Brennan D, Lewis RP, Barclay M, Weirman C, et al. The State-of-the-Art of Sensors and Environmental Monitoring Technologies in Buildings. Sensors. 2019;19(17):3648.

2. Ostachowicz W, Soman R, Malinowski P. Optimization of sensor placement for structural health monitoring: A review. Structural Health Monitoring. 2019;18(3):963-88.

3. Sanchez J, Andrade C, Fullea J. Hydrothermal monitoring using embedded sensors of the actual roof system of the Prado Museum. Constr Build Mater. 2010;24(12):2579-89.
4. Udwadia F. OPTIMAL SENSOR LOCATIONS FOR GEOTECHNICÀL AND STROCTUR. iL IDENTIFICATION. 1984.

5. Kammer DC. Sensor placement for on-orbit modal identification and correlation of large space structures. Journal of Guidance, Control, and Dynamics. 1991;14(2):251-9.

6. Papadimitriou C, Beck JL, Au S-K. Entropy-based optimal sensor location for structural model updating. Journal of Vibration and Control. 2000;6(5):781-800.

7. Heredia-Zavoni E, Montes-Iturrizaga R, Esteva L. Optimal instrumentation of structures on flexible base for system identification. Earthquake engineering \& structural dynamics. 1999;28(12):1471-82.

8. Yoganathan D, Kondepudi S, Kalluri B, Manthapuri S. Optimal sensor placement strategy for office buildings using clustering algorithms. Energy and Buildings. 2018;158:1206-25.

9. Eliades DG, Michaelides MP, Panayiotou CG, Polycarpou MM. Security-oriented sensor placement in intelligent buildings. Build Environ. 2013;63:114-21.

10. Weisbin CR, Rodriguez G, Elfes A, Smith JH. Toward a systematic approach for selection of NASA technology portfolios. Systems engineering. 2004;7(4):285-302.

11. Marteinsson B. Durability and the factor method of ISO 15686-1. Building research \& information. 2003;31(6):416-26.

12. Köppen W. Versuch einer Klassifikation der Klimate, vorzugsweise nach ihren Beziehungen zur Pflanzenwelt. Geographische Zeitschrift. 1900;6(11. H):593-611.

13. 13788: EI. Hygrothermal performance of building components and building elements-internal surface temperature to avoid critical surface humidity and interstitial condensation-calculation methods (European Committee for Standardization). 2012.

14. Noreng K. Kompakte tak. In: Byggforskserien, editor. 2018.

15. Ramstad T, J.E. T. Takformer, taktyper og oppbygning. In: Byggforskserien, editor. 2018.

16. Noreng K, Brevik B, Jelle BP. En temaveileder. Flate tak 2008. 